\title{
Langerhans cell histiocytosis of the mandible: two case reports and literature review
}

\author{
Dae-Seok Hwang ${ }^{1}$, Jun Sang Lee', Uk-Kyu Kim¹, Hae Ryoun Park², Mi Heon Ryu², \\ Ji Hye Lee', Yun-Hoa Jung' ${ }^{2}$, Gyoo Cheon Kim² \\ Departments of ${ }^{1}$ Oral and Maxillofacial Surgery and ${ }^{2}$ Translational Dental Science, \\ School of Dentistry, Pusan National University, Yangsan, Korea
}

\begin{abstract}
J Korean Assoc Oral Maxillofac Surg 2019;45:167-172)
Langerhans cell histiocytosis ( $\mathrm{LCH})$ is a rare disorder characterized by the proliferation of dendritic cells resulting in local or systemic symptoms. The clinical symptoms of patients with Langerhans cell histiocytosis depend on the site and the degree of involvement. This article describes two case histories of unifocal bony Langerhans cell histiocytosis with mandibular involvement and further discusses the appropriate management of such via a review of the literature.
\end{abstract}

Key words: Langerhans cell histiocytosis, Unifocal Langerhans cell histiocytosis

[paper submitted 2018. 5. 4 / revised 2018. 6. 17 / accepted 2018. 6. 20]

\section{Introduction}

Langerhans cell histiocytosis ( $\mathrm{LCH})$ is a rare disorder characterized by the proliferation of dendritic cells, thereby resulting in local or systemic symptoms. The most recent classification for LCH is based on a treatment protocol recommendation made by the Histiocyte Society ${ }^{1}$. Unifocal disease (eosinophilic granuloma) is a single-system (SS) disease involving a single site. The Hand-Schüller-Christian disease is a multifocal SS disease that presents with multiple sites of involvement in a single organ system, while Letterer-Siwe disease is a multifocal multisystem (MS) disease that presents as multiple involved sites in more than one organ system. MS LCH is further subdivided into $\mathrm{RO}^{+} / \mathrm{RO}^{-}$depending on whether or not a risk organ (RO) (e.g., hematopoietic sys-

\footnotetext{
Jun Sang Lee

Department of Oral and Maxillofacial Surgery, Pusan National University Dental Hospital, School of Dentistry, Pusan National University, 20 Geumoro, Mulgeum-eup, Yangsan 50612, Korea

TEL: +82-55-360-5100 FAX: +82-55-360-5104

E-mail: lj5532@hanmail.net

ORCID: https://orcid.org/0000-0001-9921-4778

(c) This is an open-access article distributed under the terms of the Creative Commons Attribution Non-Commercial License (http://creativecommons.org/ licenses/by-nc/4.0/), which permits unrestricted non-commercial use, distribution, and reproduction in any medium, provided the original work is properly cited. Copyright (C) 2019 The Korean Association of Oral and Maxillofacial Surgeons. All rights reserved.
}

tem, liver, and/or spleen) is included. Central nervous system (CNS)-risk areas include the sphenoid, orbital, ethmoid, and temporal bones, and this represents an increased risk to the central nervous system².

The clinical symptoms of patients with LCH depend on the site and the degree of involvement. Posterior mandible involvement is seen in $10 \%$ to $20 \%$ of $\mathrm{LCH}$ patients with intraoral lesions ${ }^{3}$. Oral manifestations include gingival pain, ulceration, enlargement, inflammation, or recession, and mobility of the teeth due to expansion of alveolar bone ${ }^{4}$. Dental radiographs may show discrete destructive bone lesions that can cause the teeth to appear as if they are "floating on air" . Periosteal new bone formation and slight root resorption may also be present ${ }^{6}$.

This article describes two case histories of unifocal bony LCH with mandibular involvement and further discusses the appropriate management of such cases with via a review of the literature.

\section{Cases Report}

1. Case 1

A 5-year-old female patient visited our clinic with complaining of swelling in the right mandibular region.(Fig. 

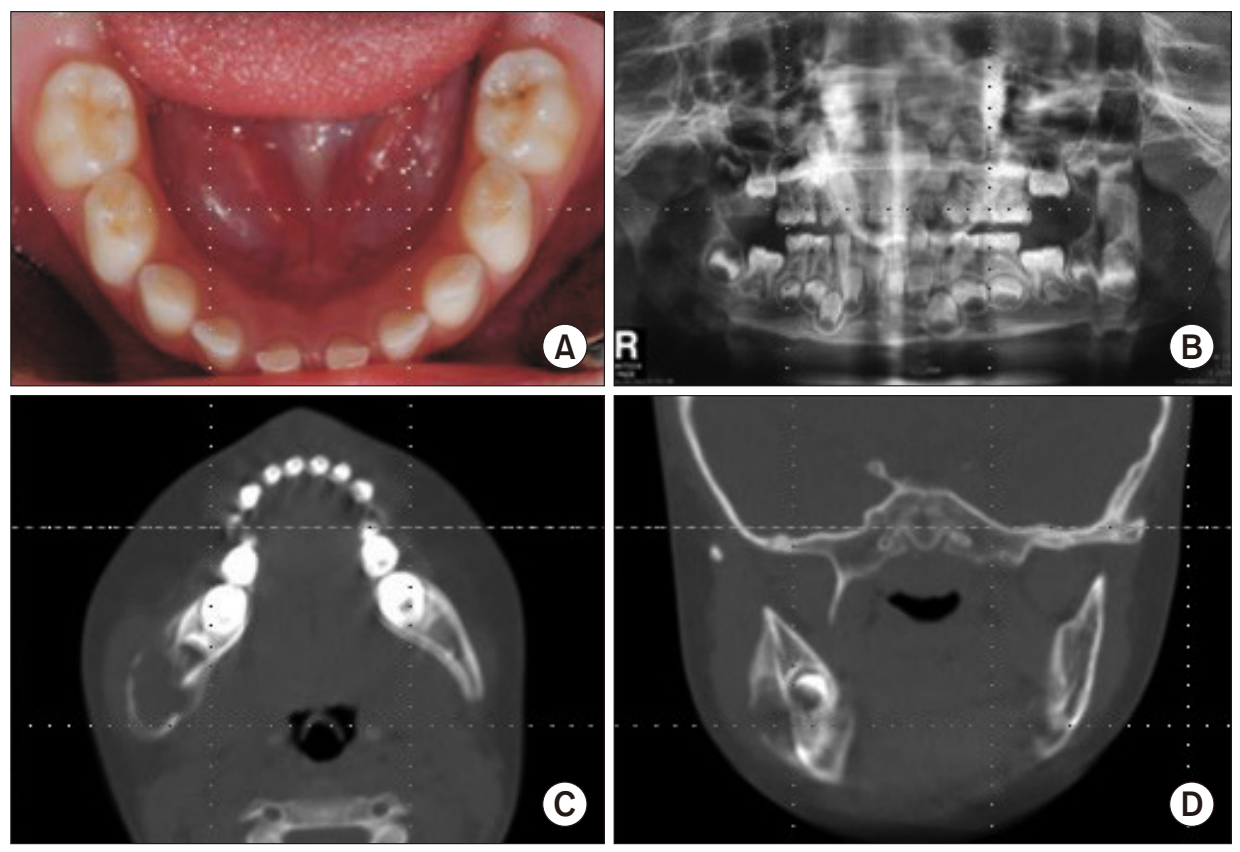

Fig. 1. Clinical and radiological feature. A. Intraoral photograph. Despite the presence of right mandibular swelling, there was no specific finding in the intraoral findings. B. Panoramic view. It was difficult to locate specific findings on panoramic examination. C, D. Osteolytic findings were observed on computed tomography (CT), including a well-defined, buccolingual expansile Iesion (C: axial view, D: coronal view). Profuse periosteal reaction was also observed around the lesion.

Dae-Seok Hwang et al: Langerhans cell histiocytosis of the mandible: two case reports and literature review. J Korean Assoc Oral Maxillofac Surg 2019
1) The patient was initially evaluated in the local pediatric clinic, and her symptoms were alleviated after a course of antibiotics. However, her symptoms returned, and the patient was admitted to a nearby university dental hospital. The patient underwent numerous tests, including computed tomography (CT), and she finally visited our hospital because of suspected malignancy. The patient had no medical history or prior systemic symptoms (e.g., fever, weight loss, skin rash, or polyuria). Clinical examination revealed swelling of the right mandible and pain in the affected area. On panoramic examination, specific findings were difficult to locate, but osteolytic findings were observed on CT, including a welldefined, buccolingual, expansile lesion. A profuse periosteal reaction was also observed around the lesion. The following laboratory tests were performed: complete blood count with differential, chemistries with liver and renal function and electrolytes, total protein, albumin, quantitative immunoglobulins, erythrocyte sedimentation rate, lactate dehydrogenase, ferritin, uric acid, and urinalysis. An incisional biopsy was performed and revealed $\mathrm{LCH}$ (CD1a/S-100 positive) on immunohistological staining.(Fig. 2) The patient was transferred to the pediatric department to clarify the extent of her disease and to determine the appropriate treatment method. Systemic examinations (e.g., magnetic resonance imaging [MRI] and bone scan) were performed, and the patient was diagnosed with unifocal disease. After corticosteroid therapy (prednisolone $5 \mathrm{mg} \times 2.5 \mathrm{Tab}$. three times a day for $1 \mathrm{month}$ ), the patient is in complete remission; the bone scans reveal no

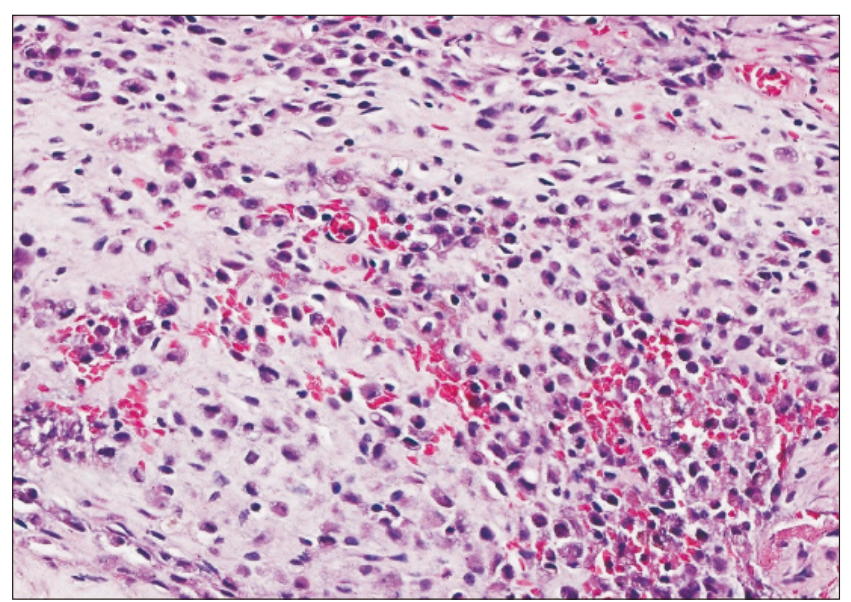

Fig. 2. Histologic feature. Langerhans cells and eosinophils are densely infiltrated. It was proved to be Langerhans cell histiocytosis (CD1a/S-100 positive) on additional immunohistological staining (H\&E staining, $\times 200)$.

Dae-Seok Hwang et al: Langerhans cell histiocytosis of the mandible: two case reports and literature review. J Korean Assoc Oral Maxillofac Surg 2019

abnormal uptake in the right mandible, and the MRI shows no definite findings suggestive of active LCH.(Fig. 3)

\section{Case 2}

A 9-year-old male patient was referred to our clinic from the Department of Pediatric Dentistry due to a history of unhealed mandible swelling, mobility of a deciduous molar tooth, and gingival swelling.(Fig. 4) One month prior to presentation, the patient experienced pain while touching 


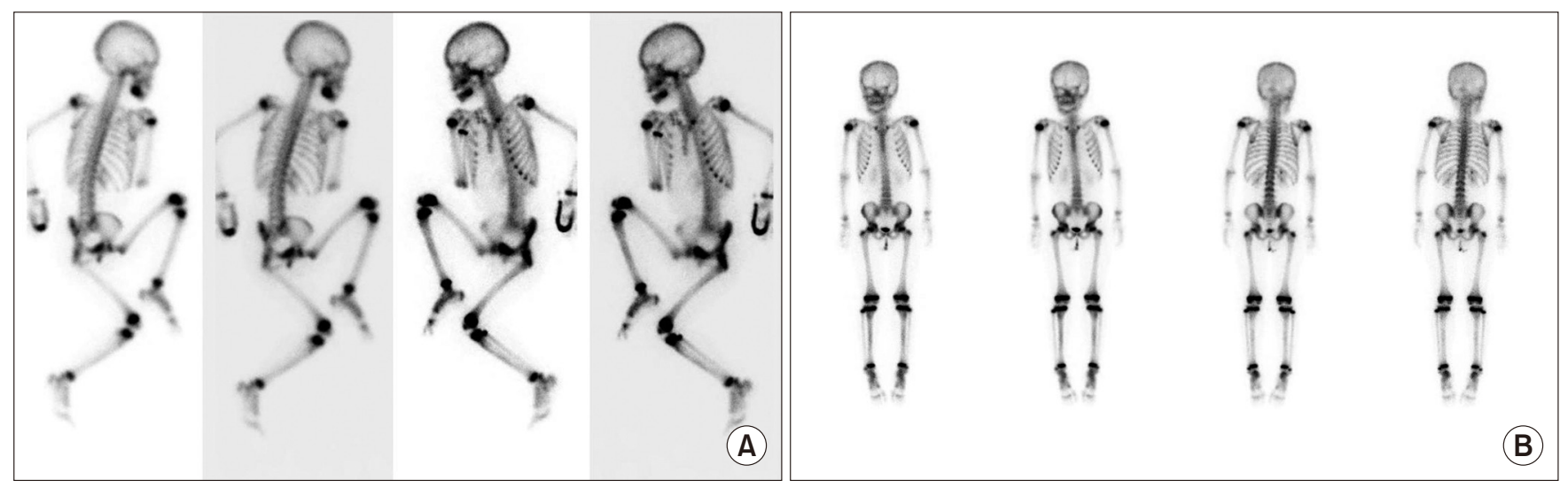

Fig. 3. Bone scan images. A. Before therapy. A focal uptake was observed in the right mandible. B. After therapy. No abnormal uptake was observed.

Dae-Seok Hwang et al: Langerhans cell histiocytosis of the mandible: two case reports and literature review. J Korean Assoc Oral Maxillofac Surg 2019
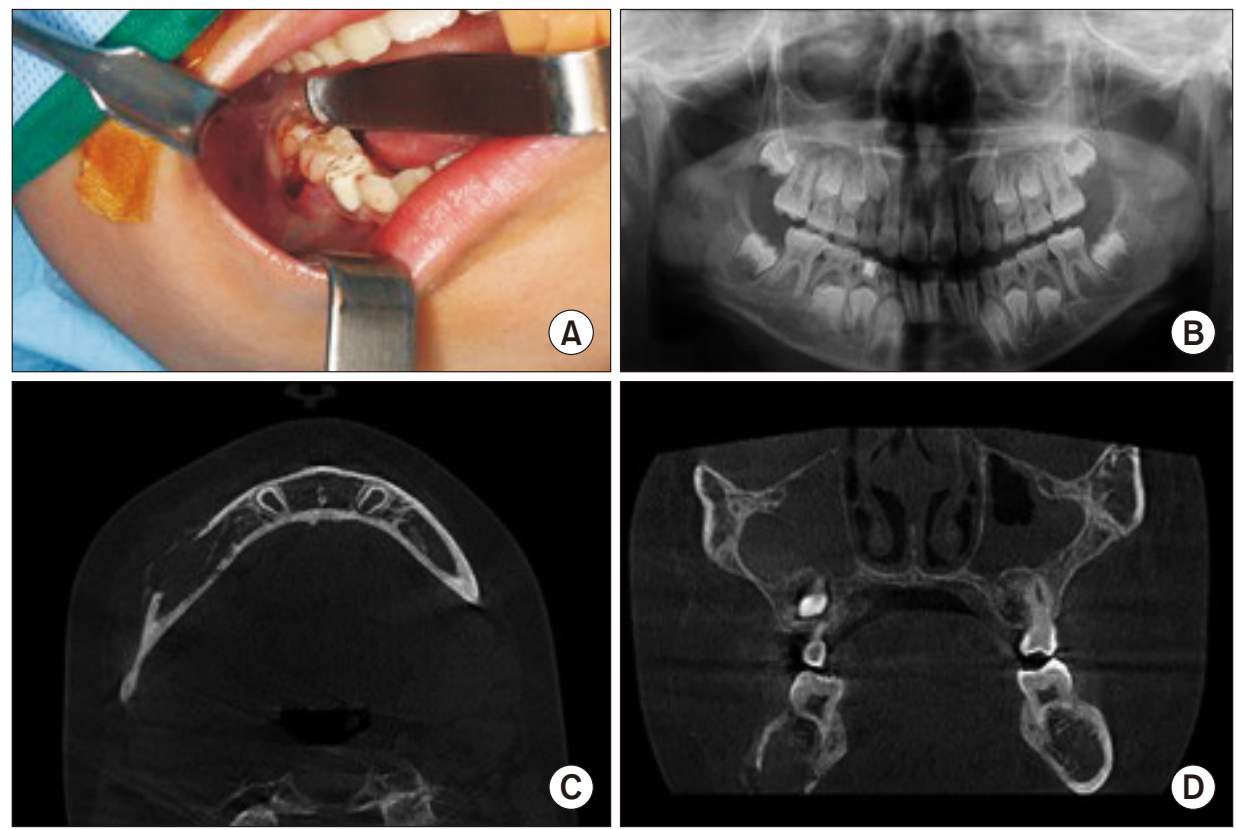

Fig. 4. Clinical and radiological feature. A. Intraoral photograph. Clinical examination revealed swelling of the right mandible, pain in the affected area, mobility of \#85, and gingival swelling and bleeding. B. Panoramic view. It was difficult to locate specific findings on panoramic examination. C, D. Osteolytic findings were observed on computed tomography (CT), including a welldefined, buccolingual expansile lesion (C: axial view, D: coronal view). Profuse periosteal reaction was also observed around the lesion.

Dae-Seok Hwang et al: Langerhans cell histiocytosis of the mandible: two case reports and literature review. J Korean Assoc Oral Maxillofac Surg 2019 his gingiva, and he visited a local dental clinic because the symptoms did not subside. The patient underwent endodontic treatment on \#84, which was performed 2 years ago. Antibiotics were repeatedly prescribed by the local dental clinic. After a CT image revealed an abnormality, the patient was transferred to our clinic. Clinical examination revealed swelling of the right mandible, pain in the affected area, mobility of \#85, and gingival swelling and bleeding. Panoramic examination revealed no specific findings, but osteolytic findings were observed on CT, including a well-defined, buccolingual, expansile lesion. A profuse periosteal reaction was also observed around the lesion. The following laboratory tests were performed: complete blood count with differential, chemistries with liver and renal function and electrolytes, total protein, albumin, quantitative immunoglobulins, erythrocyte sedimentation rate, lactate dehydrogenase, ferritin, uric acid, and urinalysis. An incisional biopsy with the patient under general anesthesia confirmed the presence of LCH (CD1a/S-100 positive).(Fig. 5) The patient was transferred to the pediatric department in order to determine the extent of the disease and the appropriate treatment protocol. Systemic examinations (e.g., MRI and bone scan) were performed, and the patient was diagnosed with unifocal disease. Corticosteroid therapy (prednisolone $5 \mathrm{mg} \times 2.5 \mathrm{Tab}$. three times a day for 1 month) was administered. After 6 months, several suspicious enlarged bilateral lymph nodes in the neck, mediastinum, and both lung hilar areas were noted, and the patient was considered to be in partial remission. No significant 
findings were discovered during the patient's follow-up period.(Fig. 6)

\section{Discussion}

$\mathrm{LCH}$ is a rare disease, and the true incidence is unknown. According to a nationwide retrospective survey conducted in Korea, $\mathrm{LCH}$ has been reported to occur in about 24 cases per year (603 patients between 1986 and 2010). The incidence was greater in male patients than in female patients (ratio of 1.4:1), and the median age at diagnosis was 65 months. The bone was the most frequently affected organ $(80 \%)^{7}$.

The pathogenesis of $\mathrm{LCH}$ is unclear, and recent studies suggested that $\mathrm{LCH}$ is a monoclonal neoplasm because a $\mathrm{V} 600 \mathrm{E}$ mutation is repeatedly found in the rapidly acceler-

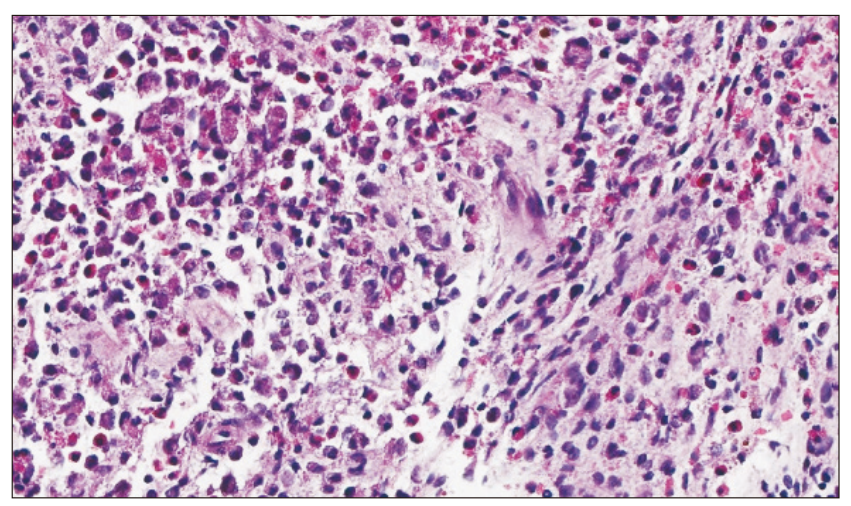

Fig. 5. Histologic feature. Langerhans cells and eosinophils are densely infiltrated. It was proved to be Langerhans cell histiocytosis (CD1a/S-100 positive) on additional immunohistological staining (H\&E staining, $\times 200)$.

Dae-Seok Hwang et al: Langerhans cell histiocytosis of the mandible: two case reports and literature review. J Korean Assoc Oral Maxillofac Surg 2019 ated fibrosarcoma isoform B (BRAF), which regulates cell survival, proliferation, motility, and cell differentiation in cell signals $^{8}$.

Oral symptoms are common in $\mathrm{LCH}$, and they are the usual chief complaints of patients upon their initial visit to the clinic. Patients usually present with pain and swelling. Radiographic images may reveal "floating teeth" in advanced disease, while destructive, ill-defined, osteolytic lesions are commonly found in a panoramic radiological view. However, it is difficult to discern buccolingual periosteal reactions on $\mathrm{x}$-rays. Periosteal reaction and "punch-out" radiolucency without a corticated border are clearly observed on CT images. Due to the destructive nature of $\mathrm{LCH}$, it is commonly confused with osteomyelitis or malignancy. Therefore, a differential diagnosis based on patient age and radiologic features is useful. Squamous cell carcinoma commonly shows a solitary ill-defined radiolucency, and it may be associated with a soft tissue mass. Sequestrum is a "hallmark" manifestation of osteomyelitis. In particular, $\mathrm{LCH}$ must be differentiated from other histological and dendritic cell diseases by histopathologic and immunophenotypic findings (CD1a, S-100) on biopsy. In our cases, each patient presented with a destructive, ill-defined osteolytic lesion, periosteal reaction on CT images, and a positive immunophenotype (CD1a, $\mathrm{S}-100)$ reaction on the incisional biopsy samples. Hence, a diagnosis of LCH could be confirmed.

SS LCH has a good prognosis, with 5-year overall survival rates in $\mathrm{SS}, \mathrm{MS}^{-\mathrm{RO}^{-}}$, and $\mathrm{MS}^{-\mathrm{RO}^{+}}$groups being $99.8 \%$, $98.4 \%$, and $77.0 \%$, respectively, and the 5-year recurrence rates are $17.9 \%, 33.5 \%$, and $34.3 \%$, respectively ${ }^{7}$. Treatment is dependent on the degree of organ involvement, solitary

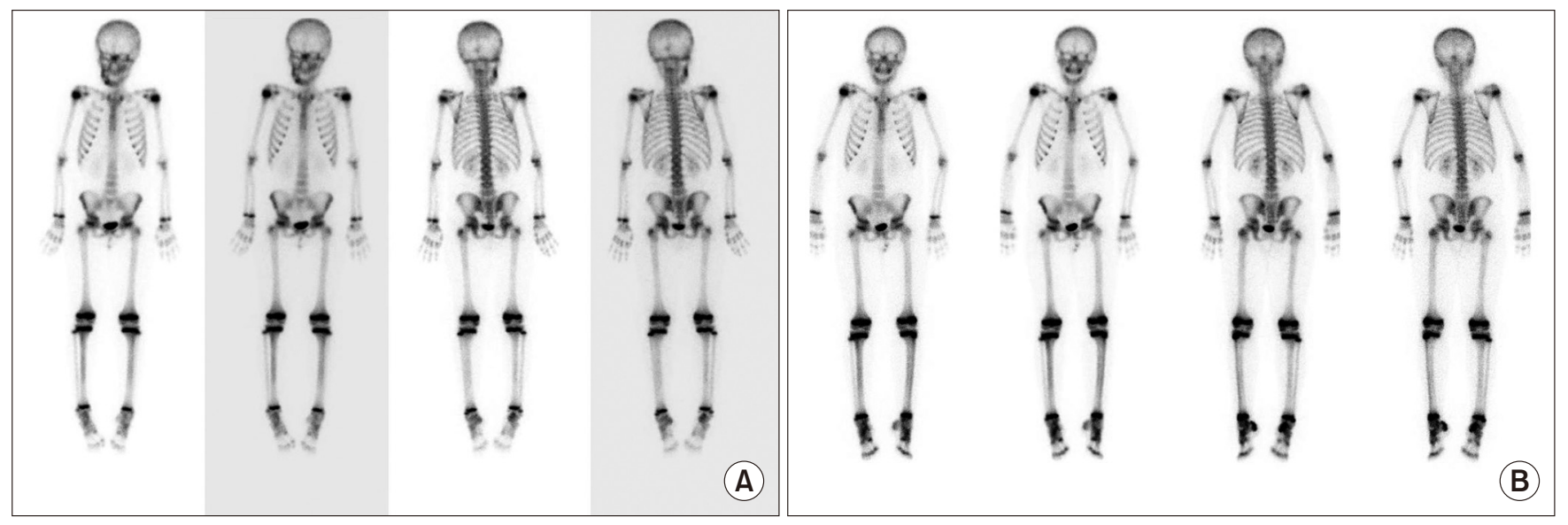

Fig. 6. Bone scan images. A. Before therapy. A focal uptake was observed in the right mandible. B. After therapy. No abnormal uptake was observed.

Dae-Seok Hwang et al: Langerhans cell histiocytosis of the mandible: two case reports and literature review. J Korean Assoc Oral Maxillofac Surg 2019 
or multiple lesions, and higher risk lesions. There is no universally accepted protocol for the treatment of solitary LCH lesions without CNS involvement (orbits, mastoids, or temporal bones) due to its good prognosis ${ }^{9}$. Numerous treatment options include observation only, surgical curettage, radiation therapy, steroid injections, and chemotherapy. Solitary lesions are often treated with curettage after biopsy, and they have shown low rates of recurrence. However, a minimally aggressive approach has often been suggested as of late ${ }^{9,10}$. Hence, after systemic involvement evaluation in both of the present cases, the primary treatment consisted of steroid medication (prednisolone). Higher risk patients with MS disease and those with CNS-risk bone involvement require systemic therapy with vinblastine and prednisone rather than surgery, radiotherapy, or single-agent chemotherapy ${ }^{11}$.

Due to the low incidence of LCH, multicenter studies are essential for establishing appropriate treatment protocols. Although there are several retrospective LCH epidemiological studies in Korea, research in the dental field is rare, and there are no detailed dental guidelines. However, several guidelines have been published, and they recommend monitoring tooth development and jaw growth in the management of jaw involvement and confirmed $\mathrm{LCH}^{12}$. Studies on LCH diagnosed through oral symptoms, as well as those describing episodes that patients experience before the diagnosis of $\mathrm{LCH}$, will be particularly significant.

Early screening and a differential diagnosis including LCH are essential for young or pediatric patients with osteolytic lesions. We recommend a pediatric transfer for patients diagnosed with $\mathrm{LCH}$ for a thorough systemic evaluation of possible multiple organ involvement. In addition, our hospital recommends systemic steroid medication as a treatment protocol.

\section{ORCID}

Dae-Seok Hwang, https://orcid.org/0000-0001-6899-1769

Jun Sang Lee, https://orcid.org/0000-0001-9921-4778

Uk-Kyu Kim, https://orcid.org/0000-0003-1251-7843

Hae Ryoun Park, https://orcid.org/0000-0003-1908-0824

Mi Heon Ryu, https://orcid.org/0000-0003-1283-9762

Ji Hye Lee, https://orcid.org/0000-0002-3107-5940

Yun-Hoa Jung, https://orcid.org/0000-0003-4431-6763

Gyoo Cheon Kim, https://orcid.org/0000-0003-3568-3529

\section{Authors' Contributions}

D.S.H. and J.S.L. participated in data collection and wrote the manuscript. U.K.K., H.R.P., M.H.R., J.H.L., Y.H.J., and G.C.K. participated in the study design and performed the radiologic and histologic analysis. All authors read and approved the final manuscript.

\section{Acknowledgements}

This study was supported by a clinical research grant from Pusan National University Dental Hospital.

\section{Conflict of Interest}

No potential conflict of interest relevant to this article was reported.

\section{References}

1. Favara BE, Feller AC, Pauli M, Jaffe ES, Weiss LM, Arico M, et al. Contemporary classification of histiocytic disorders. The WHO Committee On Histiocytic/Reticulum Cell Proliferations. Reclassification Working Group of the Histiocyte Society. Med Pediatr Oncol 1997;29:157-66.

2. Grois N, Pötschger U, Prosch H, Minkov M, Arico M, Braier J, et al. Risk factors for diabetes insipidus in langerhans cell histiocytosis. Pediatr Blood Cancer 2006;46:228-33.

3. Hartman KS. Histiocytosis X: a review of 114 cases with oral involvement. Oral Surg Oral Med Oral Pathol 1980;49:38-54.

4. Ardekian L, Peled M, Rosen D, Rachmiel A, Abu el-Naaj I, Laufer D. Clinical and radiographic features of eosinophilic granuloma in the jaws: review of 41 lesions treated by surgery and low-dose radiotherapy. Oral Surg Oral Med Oral Pathol Oral Radiol Endod 1999;87:238-42.

5. Guiglia R, Pizzo G, Aricò M, Maresi E, Compilato D, Campisi G. Bifocal manifestation of eosinophilic granuloma in a pediatric patient. Med Sci Monit 2009;15:CS95-9.

6. Dagenais M, Pharoah MJ, Sikorski PA. The radiographic characteristics of histiocytosis X. A study of 29 cases that involve the jaws. Oral Surg Oral Med Oral Pathol 1992;74:230-6.

7. Kim BE, Koh KN, Suh JK, Im HJ, Song JS, Lee JW, et al.; Korea Histiocytosis Working Party. Clinical features and treatment outcomes of Langerhans cell histiocytosis: a nationwide survey from Korea Histiocytosis Working Party. J Pediatr Hematol Oncol 2014;36:125-33.

8. Badalian-Very G, Vergilio JA, Degar BA, MacConaill LE, Brandner B, Calicchio ML, et al. Recurrent BRAF mutations in Langerhans cell histiocytosis. Blood 2010;116:1919-23.

9. Yasko AW, Fanning CV, Ayala AG, Carrasco CH, Murray JA. Percutaneous techniques for the diagnosis and treatment of localized Langerhans-cell histiocytosis (eosinophilic granuloma of bone). J Bone Joint Surg Am 1998;80:219-28.

10. Karagoz Guzey F, Bas NS, Emel E, Alatas I, Kebudi R. Polyostotic monosystemic calvarial and spinal langerhans' cell histiocytosis treated by surgery and chemotherapy. Pediatr Neurosurg 2003;38:206-11.

11. Gadner H, Minkov M, Grois N, Pötschger U, Thiem E, Aricò M, et al. Therapy prolongation improves outcome in multisystem Lang- 
erhans cell histiocytosis. Blood 2013;121:5006-14.

12. Haupt R, Minkov M, Astigarraga I, Schäfer E, Nanduri V, Jubran R, et al.; Euro Histio Network. Langerhans cell histiocytosis (LCH): guidelines for diagnosis, clinical work-up, and treatment for patients till the age of 18 years. Pediatr Blood Cancer 2013;60:175-84.
How to cite this article: Hwang DS, Lee JS, Kim UK, Park HR, Ryu MH, Lee JH, et al. Langerhans cell histiocytosis of the mandible: two case reports and literature review. J Korean Assoc Oral Maxillofac Surg 2019;45:167-72. https://doi.org/10.5125/jkaoms.2019.45.3.167 